\title{
The relationship of neurodevelopmental impairment to concurrent early childhood outcomes of extremely preterm infants
}

\author{
Matthew A. Rysavy $\mathbb{D}^{1} \cdot$ Tarah T. Colaizy $^{1}$ - Carla M. Bann ${ }^{2}$ - Sara B. DeMauro ${ }^{3}$ - Andrea F. Duncan ${ }^{3}$.

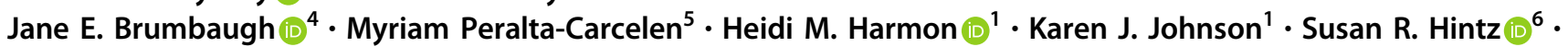 \\ Betty R. Vohr ${ }^{7}$. Edward F. Bell (D) $^{1}$ - for the Eunice Kennedy Shriver National Institute of Child Health and Human \\ Development Neonatal Research Network
}

Received: 27 August 2020 / Revised: 19 January 2021 / Accepted: 4 February 2021 / Published online: 23 March 2021

(c) The Author(s), under exclusive licence to Springer Nature America, Inc. 2021

\begin{abstract}
Objective Determine how neurodevelopmental impairment (NDI) relates to concurrent outcomes for children born extremely preterm.

Study design Retrospective cohort study children born 22 0/7-26 6/7 weeks' gestation at NICHD Neonatal Research Network hospitals. Outcomes were ascertained at 18-22 months' corrected age.

Result Of 6562 children, 2618 (40\%) died and 441 (7\%) had no follow-up. Among the remaining 3483 children, 825 (24\%), 1576 (45\%), 657 (19\%), and 425 (12\%) had no, potential/mild, moderate, and severe NDI, respectively. Rehospitalization, respiratory medications, surgery, and medical support services were associated with greater NDI severity but affected $>10 \%$ of children without NDI. Rehospitalization occurred in 40\% of children with no NDI (mean (SD): 1.7 (1.3) episodes).

Conclusion Medical, functional, and social outcomes at 18-22 months' corrected age were associated with NDI; however, many children without NDI were affected. These data should contribute to counseling families and the design of studies for childhood outcomes beyond NDI.
\end{abstract}

The names and affiliations for the members of the Eunice Kennedy Shriver National Institute of Child Health and Human Development Neonatal Research Network can be found in Supplementary information.

Parts of this work were presented at the 2017 Pediatric Academic Societies meeting.

Supplementary information The online version contains supplementary material available at https://doi.org/10.1038/s41372021-00999-7.

Matthew A. Rysavy

matthew-rysavy@uiowa.edu

1 Stead Family Department of Pediatrics, University of Iowa, Iowa, IA, USA

2 Statistics and Epidemiology Unit, RTI International, Research Triangle Park, NC, USA

3 Department of Pediatrics, University of Pennsylvania, Philadelphia, PA, USA

\section{Introduction}

Neurodevelopmental impairment (NDI) is among the most common outcomes reported in studies of neonatal prognosis and therapy. Guidelines recommend discussing NDI in antenatal discussions about what to expect if an infant survives [1]. The outcome of NDI has also become a standard primary endpoint of neonatal clinical trials [2]. Although definitions vary among studies, NDI is commonly defined as having one or more of the following: cerebral palsy, blindness, deafness, or a low score on an assessment of cognitive, language, or motor development (e.g., the Bayley Scales of Infant and Toddler Development) [3].

4 Department of Pediatric and Adolescent Medicine, Mayo Clinic, Rochester, MN, USA

5 Department of Pediatrics, University of Alabama at Birmingham, Birmingham, AL, USA

6 Department of Pediatrics, Stanford University, Palo Alto, CA, USA

7 Department of Pediatrics, Brown University, Providence, RI, USA 
Some parents, researchers, and clinicians have questioned whether NDI should be extensively used as the primary outcome of prognostic and therapeutic research and whether it adequately represents the concerns of patients, families, and society [4-7]. Diagnoses such as cerebral palsy and developmental scores may not reflect the day-today impact of premature birth in areas such as the need for medical care (e.g., appointments, surgeries, rehospitalizations, and medicines) and daily functioning.

The Eunice Kennedy Shriver National Institute of Child Health and Human Development (NICHD) Neonatal Research Network (NRN) collects detailed follow-up outcome data for children born extremely preterm (22-26 weeks' gestation) at participating NRN centers and so provides a resource for describing the early lives of families of children with and without NDI. The purpose of this study was to describe concurrent outcomes of children born extremely preterm with and without diagnoses of NDI in order to guide clinical care and future research.

\section{Methods}

\section{Population}

This study included children born at $220 / 7$ to $266 / 7$ weeks' gestation between 5/1/2006 and 6/30/2012 in 21 US academic centers participating in the NRN. The end date for the study was defined by the last births with follow-up examinations taking place at 18-22 months' corrected age (for infants born after 7/1/2012, the timing of NRN follow-up assessments was changed from 18-22 months to 22-26 months' corrected age). Infants with major congenital anomalies were excluded from the analysis, as factors besides prematurity may impact their outcomes. The institutional review board at each participating site approved NRN in-hospital and follow-up protocols.

\section{Data collection}

Trained research personnel at each center obtained data for all liveborn extremely preterm infants using previously described protocols $[8,9]$. Gestational age at birth was defined by the best obstetric estimate. Small for gestational age was defined as $<10$ th percentile by gestational age at birth using sex-specific growth charts [10]. Neonatal morbidities included intraventricular hemorrhage (IVH) grade 3-4 [11], necrotizing enterocolitis (NEC) requiring surgical intervention, retinopathy of prematurity (ROP) stage $\geq 3$ [12], and severe bronchopulmonary dysplasia (BPD) defined as supplemental oxygen $\geq 30 \%$ or positive pressure [13].

Follow-up assessments at 18-22 months' corrected age consisted of standardized neurological examination and administration of the Bayley Scales of Infant and Toddler Development, third edition (Bayley-III) by annually certified examiners [14]. Additional information was obtained through questionnaires, structured interviews, and review of children's medical records. This information included: postdischarge hospitalizations, medical subspecialty care, medications, and surgeries; home medical equipment use; medical support service utilization; child care arrangements; and information on feeding. Data on hospitalizations, subspecialist visits, and surgeries reflected the duration between initial neonatal intensive care discharge and follow-up evaluation. Medication data reflected use during the 3 months prior to follow-up. Medication data were collected using categories defined by indication without specifying medication names or dosages. Anti-reflux medications included proton-pump inhibitors, $\mathrm{H} 2$ antagonists, and prokinetics. Medications for asthma or BPD included inhaled bronchodilators and corticosteroids. Anti-seizure medications included anticonvulsants; thyroid medications included levothyroxine; and anti-spasticity medications included baclofen. Information on medical equipment was recorded if the child used the equipment at follow-up or if it had been ordered for use at that time. Information on medical support service use at the time of follow-up, child care during the month prior to follow-up, and feeding habits at the time of follow-up were reported by the primary caretaker.

\section{NDI classification}

NDI was described using the definitions in Table 1. Components of NDI included the Bayley-III cognitive composite score, diagnosis of cerebral palsy, modified Gross Motor Function Classification System (GMFCS) score [15, 16], blindness and deafness. The Bayley-III cognitive composite score has a standardized mean of 100 with standard deviations (SDs) of 15 points, which have been used to define NDI cutoffs ("moderate NDI" being defined as $>1$ SD below the standardized mean [score <85], "severe NDI" as $>2$ SD below the standardized mean [score <70]) [17, 18]. Because of controversy about the appropriateness of normative reference cutoffs for Bayley-III scores in our population [19], a "potential/mild NDI" category was defined as a cognitive composite score $\leq 1 \mathrm{SD}$ below the mean to avoid potential inclusion of children with cognitive composite scores near those used to define NDI in the "no NDI" group. All BayleyIII norms were based on the child's adjusted age. Per NRN protocols, a modified GMFCS score was determined for all children and ranged from 0 (no abnormalities) to 5 (most severe), with the category of "possible level 1" being reserved for children with toe walking or asymmetric walking, suggesting the potential for mild diplegia or hemiplegia but not diagnostic of cerebral palsy at 18-22 months' corrected age [20]. The latter was also used to characterize the "potential/ 
Table 1 Classification of Neurodevelopmental Impairment.

\begin{tabular}{llllll}
\hline NDI classification & Characteristic & & & \\
\cline { 2 - 6 } & \multicolumn{1}{l}{ Bayley-III Cognitive Score } & GMFCS & CP & Vision impairment & Hearing impairment \\
\hline Severe & $<70$ & Level 4 or 5 & Severe & $\begin{array}{l}\text { Bilateral <20/200, despite } \\
\text { correction }\end{array}$ & $\begin{array}{l}\text { Severe, bilateral, cannot be } \\
\text { corrected }\end{array}$ \\
Moderate & $70-84$ & Level 2 or 3 & Moderate & N/A & N/A \\
Potential/Mild & $85-99$ & Level 1 or Possible & Mild & N/A & N/A \\
No & $\geq 100$ & Level 1 & No & N/A & N/A \\
\hline
\end{tabular}

NDI classification was determined by the presence of the most severe characteristic that met criteria. For example, a child with bilateral blindness $<20 / 200$ was classified as having severe NDI regardless of Bayley-III cognitive score or diagnosis of CP.

The GMFCS examination was performed at follow-up for all children regardless of cerebral palsy diagnosis. Children with a cerebral palsy diagnosis therefore represent a subset of children with abnormal GMFCS examination. Cerebral palsy was defined as abnormality in the neuromuscular exam (except for isolated low tone) with associated functional impairment. Severity is based on GMFCS level (mild = level 1; moderate $=$ level 2 or 3 ; severe $=$ level 4 or 5 ).

NDI neurodevelopmental impairment, Bayley-III Bayley Scales of Infant and Toddler Development, third edition, GMFCS Gross Motor Function Classification Scale, $C P$ cerebral palsy.

mild NDI" group in order to avoid including children with non-diagnostic examiner concerns about motor function in the "no NDI" group. Functional blindness was defined by caretaker report with an exam consistent with bilateral visual acuity $<20 / 200$ despite correction. Functional deafness was defined as severe, bilateral hearing loss with or without amplification per caretaker report and consistent with the exam.

\section{Statistical analysis}

Differences in the prevalence of outcomes among children in the four NDI groups (none, potential/mild, moderate, and severe NDI) were compared using Cochran-MantelHaenszel tests (for categorical variables) and ANCOVA (for continuous variables), as appropriate. The analyses were adjusted for gestational age at birth (in completed weeks), known to be correlated with NDI classification and expected to correlate with several outcomes. A $p$ value $<0.05$ was considered statistically significant. Corrections for multiple comparisons were not conducted. All analyses were conducted using SAS version 9.4.

\section{Results}

There were 6542 children born at 22-26 weeks' gestation who were eligible for inclusion. Of these, 2618 (40\%) died and $441(7 \%)$ had incomplete follow-up information. Of the remaining 3483 children, 825 (24\%), 1576 (45\%), 657 (19\%), and 425 (12\%) had no, potential/mild, moderate, and severe NDI, respectively.

Components of NDI among the children in this cohort are described in Table 2. In all categories, the most prevalent determinant of NDI classification was the Bayley-III cognitive composite score. Cerebral palsy was diagnosed in $6 \%, 18 \%$, and $49 \%$ of children with potential/mild, moderate, and severe NDI, respectively. Blindness and deafness were present among $12 \%$ and $24 \%$ of children, respectively, with severe NDI.

Among infants surviving to follow-up, 17/27 (63\%), 106/ 253 (42\%), 293/786 (37\%), 348/1122 (31\%), and 318/1295 (25\%) of children born at $22,23,24,25$, and 26 weeks' gestation had moderate or severe NDI. As shown in Table 3, severity of NDI was associated with lower birth weight, male sex, 1-minute Apgar score $\leq 3$, no exposure to antenatal corticosteroids, small for gestational age, maternal self-identification as non-white race, and lack of private insurance $(p<0.001)$. Severity of NDI was also associated with increased rates of grade 3-4 IVH, surgical NEC, stage $\geq 3$ ROP, and severe BPD.

NDI severity was associated with several concurrent outcomes at 18-22 months' corrected age overall (Table 4) and at each gestational age (Supplemental Tables A1-A4). Rehospitalization following discharge from the neonatal intensive care unit was common for all children born extremely preterm, regardless of NDI severity, with 331/ $825(40 \%)$ of children with no NDI and 300/425 (70\%) of children with severe NDI rehospitalized by 18-22 months' corrected age. Children without NDI were rehospitalized, on average, 1.7 times (SD 1.3) before 18-22 months' corrected age and children with severe NDI 3.2 (SD 3.1) times. The most common reason for rehospitalization was respiratory disease. Regardless of NDI status, large proportions of children in each NDI category $(17-31 \%)$ used medications at 18-22 months' corrected age to treat asthma or BPD. Similarly, tympanostomy tube placement (rates of 9-16\% across NDI categories) and hernia repair (rates of 11-17\% across NDI categories) were common among all children born extremely preterm, regardless of NDI status. 
Table 2 Rates of Each Component of Neurodevelopmental Impairment.

\begin{tabular}{|c|c|c|c|c|}
\hline Component & $\begin{array}{l}\text { No NDI } \\
(N=825) \\
n(\%)\end{array}$ & $\begin{array}{l}\text { Potential/Mild NDI } \\
(N=1576) \\
n(\%)\end{array}$ & $\begin{array}{l}\text { Moderate NDI } \\
(N=657) \\
n(\%)\end{array}$ & $\begin{array}{l}\text { Severe NDI } \\
(N=425) \\
n(\%)\end{array}$ \\
\hline \multicolumn{5}{|c|}{ Bayley-III Cognitive } \\
\hline Score $100+$ & $825(100)$ & 117 (7) & $3(0)$ & $13(3)^{\mathrm{a}}$ \\
\hline Score $85-99$ & - & 1459 (93) & $27(4)$ & $27(7)^{\mathrm{a}}$ \\
\hline Score $70-84$ & - & - & $627(95)$ & $35(9)^{\mathrm{a}}$ \\
\hline Score $<70$ & - & - & - & $329(81)^{\mathrm{a}}$ \\
\hline \multicolumn{5}{|l|}{ GMFCS level } \\
\hline Level 0 & $825(100)$ & $1202(76)$ & $407(62)$ & $109(26)^{b}$ \\
\hline Level $1^{\mathrm{c}}$ & - & $374(24)$ & $170(26)$ & $105(25)^{b}$ \\
\hline Level 2-3 & - & - & $80(12)$ & $122(29)^{b}$ \\
\hline Level 4-5 & - & - & - & $88(21)^{b}$ \\
\hline \multicolumn{5}{|l|}{ CP level } \\
\hline None & $825(100)$ & 1475 (94) & $541(82)$ & $219(52)^{\mathrm{b}}$ \\
\hline Mild & - & $101(6)$ & $76(12)$ & $37(9)^{\mathrm{b}}$ \\
\hline Moderate & - & - & $40(6)$ & $79(19)^{\mathrm{b}}$ \\
\hline Severe & - & - & - & $89(21)^{b}$ \\
\hline Blindness & - & - & - & $51(12)^{\mathrm{d}}$ \\
\hline Deafness & - & - & - & $102(24)^{\mathrm{e}}$ \\
\hline
\end{tabular}

Bayley-III Bayley Scales of Infant and Toddler Development, third edition, GMFCS Gross Motor Function Classification Scale, $C P$ cerebral palsy.

${ }^{a}$ Of 404 children ( 21 children with severe NDI did not have Bayley-III cognitive scores).

${ }^{\mathrm{b}}$ Of 424 children ( 1 child with severe NDI did not have data on GMFCS score or CP).

"Includes "possible level 1".

${ }^{\mathrm{d}}$ Of 421 children ( 4 children with severe NDI did not have data on vision).

${ }^{\mathrm{e}} \mathrm{Of} 423$ children ( 2 children with severe NDI did not have data on hearing).
While nearly one quarter (82/361) of children with severe NDI had gastrostomy tube placement by 18-22 months' corrected age, there was evidence of functional feeding difficulties in all NDI categories and 2\% (15/ 725) of children with no NDI had a gastrostomy tube placed. With no NDI, 96\% of children could feed themselves at 18-22 months' corrected age, whereas $44 \%$ of children with severe NDI were able to feed themselves.

Use of medical equipment and medical support services was more common among children with severe NDI. Among children without NDI, 17\% utilized physical and occupational therapy at 18-22 months and $21 \%$ utilized speech therapy services. These compare to $75 \%$ and $53 \%$, respectively, among children with severe NDI. The utilization of traditional home-based or center-based daycare was much more common among children with no NDI (33\%) than those with severe NDI (11\%).

\section{Discussion}

In a cohort of children born extremely preterm, NDI severity was associated with increased rates of rehospitalization, medical subspecialty visits, surgeries, medication and equipment use, specialty medical child care, and functional feeding difficulties at 18-22 months' corrected age. However, children born extremely preterm with no diagnosis of NDI also had high rates of rehospitalization, surgery, and medical utilization.

Childhood outcomes of extremely preterm infants have been extensively studied [21]. However, few others have described non-NDI outcomes in relation to NDI diagnosis $[22,23]$. Our study raises important questions about how to best design and report studies of the outcomes of extremely premature birth. At a workshop held jointly by the Eunice Kennedy Shriver National Institute of Child Health and Human Development (NICHD), Society for Maternal-Fetal Medicine, American Academy of Pediatrics, and American College of Obstetricians and Gynecologists, participants recommended that "Physicians should recognize that the parents' views on what is a 'severe' disability may be different from those of the researchers or clinicians..." [24] Others, including the Core Outcomes in Neonatology group, have worked with key stakeholders, including families, healthcare providers, and members of society, to evaluate which outcomes of prematurity are of importance 
Table 3 Subject characteristics by neurodevelopmental impairment.

\begin{tabular}{|c|c|c|c|c|}
\hline Characteristic & $\begin{array}{l}\text { No NDI } \\
(N=825) \\
n(\%)\end{array}$ & $\begin{array}{l}\text { Potential/Mild NDI } \\
(N=1576) \\
n(\%)\end{array}$ & $\begin{array}{l}\text { Moderate NDI } \\
(N=657) \\
n(\%)\end{array}$ & $\begin{array}{l}\text { Severe NDI } \\
(N=425) \\
n(\%)\end{array}$ \\
\hline \multicolumn{5}{|l|}{ Mother } \\
\hline Age $<20$ years & $79(10)$ & $182(12)$ & $70(11)$ & $47(11)$ \\
\hline Private insurance ${ }^{* *}$ & $450(55)$ & $643(41)$ & $208(32)$ & $171(40)$ \\
\hline Received any prenatal care* & $795(96)$ & $1509(96)$ & $611(93)$ & $406(96)$ \\
\hline \multicolumn{5}{|l|}{ Race/ethnicity $^{* *}$} \\
\hline White non-Hispanic & $394(48)$ & $605(38)$ & $218(33)$ & $154(36)$ \\
\hline Black non-Hispanic & $284(35)$ & $619(39)$ & $290(44)$ & $178(42)$ \\
\hline White Hispanic & $78(9)$ & $218(14)$ & $103(16)$ & $53(12)$ \\
\hline Black Hispanic & $6(1)$ & $17(1)$ & $4(1)$ & $7(2)$ \\
\hline Other & $61(7)$ & $115(7)$ & $42(6)$ & $33(8)$ \\
\hline Diabetes $^{\mathrm{a}}$ & $39(5)$ & $67(4)$ & $28(4)$ & $18(4)$ \\
\hline Hypertension $^{\mathrm{b}}$ & $173(21)$ & $320(20)$ & $148(23)$ & $86(20)$ \\
\hline Clinical chorioamnionitis & $146(18)$ & $297(19)$ & $120(18)$ & $90(21)$ \\
\hline \multicolumn{5}{|l|}{ Infant } \\
\hline Male $^{* *}$ & $359(44)$ & $760(48)$ & $339(52)$ & $261(62)$ \\
\hline Multiple birth & $209(25)$ & $362(23)$ & $152(23)$ & $101(24)$ \\
\hline 1-min Apgar score $\leq 3^{* *}$ & 361 (44) & 699 (44) & 314 (48) & $243(57)$ \\
\hline Birth weight $(\mathrm{g})$-median, $[\mathrm{IQR}]^{* *}$ & $790(689-900)$ & $760(660-870)$ & $725(631-840)$ & $690(589-808)$ \\
\hline Small for gestational age $\mathrm{e}^{\mathrm{c}^{* *}}$ & $27(3)$ & $67(4)$ & $44(7)$ & $34(8)$ \\
\hline Antenatal steroids $\mathrm{d}^{\mathrm{***}}$ & $756(92)$ & $1407(90)$ & $551(85)$ & $368(87)$ \\
\hline Birth by c-section & $526(64)$ & $1020(65)$ & $424(65)$ & $286(67)$ \\
\hline \multicolumn{5}{|l|}{ Gestational age at birth $^{* *}$} \\
\hline 22 weeks & $1(0)$ & $9(1)$ & $10(2)$ & $7(2)$ \\
\hline 23 weeks & $33(4)$ & $114(7)$ & $45(7)$ & $61(14)$ \\
\hline 24 weeks & $147(18)$ & $346(22)$ & $162(25)$ & $131(31)$ \\
\hline 25 weeks & $273(33)$ & $501(32)$ & $214(33)$ & $134(32)$ \\
\hline 26 weeks & $371(45)$ & $606(38)$ & $226(34)$ & $92(22)$ \\
\hline IVH grade $3-4$ & $77(9)$ & $198(13)$ & $116(18)$ & $140(33)$ \\
\hline Surgical NEC & $14(2)$ & $60(4)$ & $27(4)$ & $43(10)$ \\
\hline $\mathrm{ROP} \geq$ stage 3 & $118(14)$ & $299(19)$ & $180(27)$ & $176(41)$ \\
\hline Severe BPD $^{\mathrm{e}}$ & 153 (19) & $455(29)$ & $231(35)$ & $223(53)$ \\
\hline
\end{tabular}

All values in parentheses are percentages unless indicated otherwise.

$N D I$ neurodevelopmental impairment, IQR interquartile range, $I V H$ intraventricular hemorrhage, $N E C$ necrotizing enterocolitis, $R O P$ retinopathy of prematurity, $B P D$ bronchopulmonary dysplasia.

$* p$ value for comparison across all categories $<0.05$.

$* * p$ value for comparison across all categories $<0.001$.

${ }^{\mathrm{a}}$ Includes any diagnosis of diabetes during pregnancy.

${ }^{\mathrm{b}}$ Includes chronic hypertension, gestational hypertension, pre-eclampsia, and eclampsia.

${ }^{\mathrm{c}}$ Defined as birth weight $<10$ th percentile for age and sex.

${ }^{\mathrm{d}}$ Includes receipt of any antenatal dexamethasone or betamethasone for fetal maturation, regardless of timing relative to birth or whether a full or partial course was received.

${ }^{\mathrm{e}}$ Defined as supplemental oxygen $\geq 30 \%$ or positive pressure.

to these stakeholders to collect and report in neonatal studies [25-27]. These outcomes include respiratory illnesses, readmissions, multiple operations, and the effects of a child's illness on the family [26].
Strengths of this study include the large number of infants and high rates of follow-up in the NICHD Neonatal Research Network, as well as the availability of standardized data obtained by annually certified research personnel 
Table 4 Childhood Outcomes at 18-22 Months' Corrected Age by Neurodevelopmental Impairment.

\begin{tabular}{|c|c|c|c|c|}
\hline Outcome & $\begin{array}{l}\text { No NDI } \\
(N=825) \\
n / N(\%)\end{array}$ & $\begin{array}{l}\text { Potential/Mild NDI } \\
(N=1576) \\
n / N(\%)\end{array}$ & $\begin{array}{l}\text { Moderate NDI } \\
(N=657) \\
n / N(\%)\end{array}$ & $\begin{array}{l}\text { Severe NDI } \\
(N=425) \\
n / N(\%)\end{array}$ \\
\hline \multicolumn{5}{|l|}{ Medical care since NICU discharge } \\
\hline Rehospitalized & $331(40)$ & $733 / 1574(47)$ & $328(50)$ & $300(71)$ \\
\hline Mean number (SD) & $1.7(1.3)$ & $2.0(2.9)$ & $2.2(2.1)$ & $3.2(3.1)$ \\
\hline \multicolumn{5}{|l|}{ Reason } \\
\hline Respiratory & $154 / 327(47)$ & $385 / 726(53)$ & $186 / 322(58)$ & $173 / 300(58)$ \\
\hline Neurologic & 3/327 (1) & $31 / 726(4)$ & $17 / 322(5)$ & $34 / 300(11)$ \\
\hline Surgery & $99 / 327(30)$ & $184 / 726(25)$ & $87 / 322(27)$ & $103 / 300(34)$ \\
\hline Infection & $82 / 327(25)$ & $149 / 726(21)$ & $73 / 322(23)$ & $77 / 300(26)$ \\
\hline Growth/Nutrition & $8 / 327(2)$ & $43 / 726(6)$ & $37 / 322(11)$ & $37 / 300(12)$ \\
\hline $\begin{array}{l}\text { Mean number of outpatient } \\
\text { subspecialists (SD) }\end{array}$ & $2.8(1.3)$ & $3.0(1.4)$ & $3.2(1.6)$ & $4.1(1.5)$ \\
\hline \multicolumn{5}{|l|}{ Surgeries since NICU discharge } \\
\hline Tympanostomy tubes & $88 / 725(12)$ & $149 / 1398(11)$ & $55 / 583(9)$ & $57 / 361(16)$ \\
\hline Tracheostomy & $3 / 725(0)$ & 9/1398 (1) & $9 / 583(2)$ & $27 / 361(7)$ \\
\hline Eye surgery & $37 / 725(5)$ & $116 / 1398(8)$ & $95 / 583(16)$ & $85 / 361(24)$ \\
\hline Hernia surgery & $81 / 725(11)$ & $166 / 1398(12)$ & $68 / 583(12)$ & $62 / 361(17)$ \\
\hline Gastrostomy tube & $15 / 725(2)$ & $74 / 1398(5)$ & $51 / 583(9)$ & $82 / 361(23)$ \\
\hline Fundoplication & $7 / 725(1)$ & $16 / 1398(1)$ & $12 / 583(2)$ & $23 / 361(6)$ \\
\hline Shunt for hydrocephalus & $3 / 725(0)$ & $26 / 1398(2)$ & $15 / 583(3)$ & $41 / 361(11)$ \\
\hline Bronchoscopy & $16 / 725(2)$ & $56 / 1398(4)$ & $35 / 583(6)$ & $50 / 361(14)$ \\
\hline \multicolumn{5}{|l|}{ Medication use during prior 3 months } \\
\hline Anti-reflux & $64(8)$ & $190(12)$ & $121(18)$ & $140(33)$ \\
\hline Asthma/BPD & $111 / 659(17)$ & $239 / 1213(20)$ & $117 / 487(24)$ & $81 / 264(31)$ \\
\hline Anti-seizure & $2(0)$ & $15(1)$ & $15(2)$ & $45(11)$ \\
\hline Thyroid hormone & $11(1)$ & $19(1)$ & $11(2)$ & $16(4)$ \\
\hline Anti-spasticity & $0(0)$ & $1(0)$ & $6(1)$ & $33(8)$ \\
\hline \multicolumn{5}{|l|}{ Current medical equipment } \\
\hline Apnea monitor & $1(0)$ & $22(1)$ & $10(2)$ & $23(5)$ \\
\hline Oxygen & $8(1)$ & $37(2)$ & $43(7)$ & $92(22)$ \\
\hline Ventilator/CPAP & $0(0)$ & $8(1)$ & $13(2)$ & $33(8)$ \\
\hline Wheelchair/adapted stroller & $0(0)$ & $0(0)$ & $5(1)$ & $43(10)$ \\
\hline Braces/orthotics & $18(2)$ & $96(6)$ & $72(11)$ & $113(27)$ \\
\hline Walker/stander & $1(0)$ & $14(1)$ & $24(4)$ & $71(17)$ \\
\hline Corrective lenses & $24(3)$ & $108(7)$ & $72(11)$ & $78(19)$ \\
\hline Hearing aids/cochlear implants & $8(1)$ & $23(1)$ & $13(2)$ & $60(14)$ \\
\hline \multicolumn{5}{|l|}{ Current medical support services } \\
\hline Visiting nurse & $17(2)$ & $41(3)$ & $36(5)$ & $47(11)$ \\
\hline Home nurse & $6(1)$ & $22(1)$ & $38(6)$ & $55(13)$ \\
\hline $\mathrm{OT} / \mathrm{PT}$ & 138 (17) & $525(33)$ & 307 (47) & $317(75)$ \\
\hline Speech therapy & $169(21)$ & $428(27)$ & $233(36)$ & $223(53)$ \\
\hline Social worker & $49(6)$ & $134(9)$ & $90(14)$ & $94(22)$ \\
\hline \multicolumn{5}{|c|}{ Current custody and child care arrangements } \\
\hline Under state supervision & $25(3)$ & $45(3)$ & $38(6)$ & $33(8)$ \\
\hline Center-based daycare & $131 / 824(16)$ & $210 / 1565(13)$ & $59 / 651(9)$ & $25 / 416(6)$ \\
\hline Home-based daycare & $138 / 824(17)$ & $196 / 1565(13)$ & $58 / 651(9)$ & $21 / 416(5)$ \\
\hline
\end{tabular}


Table 4 (continued)

\begin{tabular}{|c|c|c|c|c|}
\hline Outcome & $\begin{array}{l}\text { No NDI } \\
(N=825) \\
n / N(\%)\end{array}$ & $\begin{array}{l}\text { Potential/Mild NDI } \\
(N=1576) \\
n / N(\%)\end{array}$ & $\begin{array}{l}\text { Moderate NDI } \\
(N=657) \\
n / N(\%)\end{array}$ & $\begin{array}{l}\text { Severe NDI } \\
(N=425) \\
n / N(\%)\end{array}$ \\
\hline \multicolumn{5}{|l|}{ Babysitter/Au Pair } \\
\hline Relative & $121(15)$ & $228(14)$ & $81(12)$ & $51(12)$ \\
\hline Non-relative & $59(7)$ & $69(4)$ & $25(4)$ & $16(4)$ \\
\hline Medical child care ${ }^{a}$ & 4/824 (0) & $22 / 1565(1)$ & $38 / 651(6)$ & 45/416 (11) \\
\hline \multicolumn{5}{|l|}{ Current feeding status } \\
\hline Tube fed & $12(1)$ & 67 (4) & $72(11)$ & $133(31)$ \\
\hline Parenteral nutrition & $2(0)$ & $5(0)$ & $2(0)$ & $5(1)$ \\
\hline Feeds self & $790(96)$ & $1432(91)$ & $525(80)$ & $188(44)$ \\
\hline
\end{tabular}

All outcomes were significantly different $(p<0.05)$ across NDI categories after controlling for gestational age at birth (in weeks), except for parenteral nutrition.

NICU neonatal intensive care unit, $S D$ standard deviation, $B P D$ bronchopulmonary dysplasia, $C P A P$ continuous positive airway pressure, $O T$ occupational therapy, $P T$ physical therapy.

${ }^{a}$ Defined as requiring nursing or other specialized supervision either at home or in a non-home facility.

to diagnose NDI. The data included outcomes from academic medical centers across the United States representing various geographies and populations. NDI data from the NRN have been widely used in prognostic studies and clinical trials to help guide care of extremely preterm infants in the United States and around the world [28-31].

Limitations of this study include the post-hoc design of the analysis, which used only available data and precluded the ability to obtain additional information on family and parental quality of life, employment, education, relationships, health, and other outcomes. Moreover, this study was intended to be descriptive and was not designed to determine which factors affected both NDI and other outcomes at follow-up, such as neonatal morbidities or socioeconomic hardships. Importantly, follow-up data were limited to those collected at 18-22 months' corrected age and provide only a snapshot from that time. NDI diagnoses may vary over children's lives and assessments at later ages may have resulted in some children changing NDI categories [32, 33]. However, although 18-22 month outcomes may not adequately reflect long-term function or needs, data collected at 2 years' corrected age are frequently used for perinatal decision-making [1].

Unlike many other neonatal morbidities, such as IVH [11] and retinopathy of prematurity [12], NDI does not have a consensus definition. Published definitions vary widely across studies [34]. Small variations in the definition of NDI can have a substantial influence on its rate in a population and on its association with specific variables [35, 36]. Despite this, studies of NDI in children born extremely preterm are used as the basis for recommendations to make treatment decisions, including whether to direct care toward survival or palliation $[1,24]$, and are frequently used as a component of the primary outcome of major clinical trials [2]. For the purposes of our study, we presented results separately for "no NDI" and "potential/mild NDI." While the clinical significance of the "potential/mild NDI" category is debatable, at least one group has suggested using cutoffs as high as 95 for the Bayley-III cognitive composite score to indicate problems with cognitive development [37]. In our study, the designation was used to avoid misclassification of marginal cases in the "no NDI" group, which was important to study adverse outcomes among children without NDI. The definitions of NDI used in this study are similar to those used elsewhere [15] but cannot be compared with studies using different NDI definitions or criteria.

In conclusion, we found that severity of NDI was associated with several other important medical, functional, and social outcomes at 18-22 months' corrected age. However, children born extremely preterm without an NDI diagnosis had substantial medical needs following discharge that may significantly impact families and the healthcare system. These data should be useful to support counseling families and the design of studies for early childhood outcomes beyond NDI.

Acknowledgements See Supplementary Information for additional acknowledgements.

Author contributions MAR conceptualized and designed the study, interpreted and directed statistical analyses, drafted the initial manuscript, and made revisions to subsequent drafts. TTC assisted with conceptualization and design of the study, coordinated and supervised data collection, and reviewed manuscript drafts. CMB provided 
statistical input on the analysis plan, conducted statistical analyses, and reviewed manuscript drafts. KJJ and SBD, AFD, JEB, MPC, $\mathrm{HMH}, \mathrm{SRH}, \mathrm{BRV}$, and EFB coordinated and supervised data collection and reviewed manuscript drafts. All authors approved the final manuscript as submitted and agree to be accountable for all aspects of the work.

Funding This research was supported by the National Institutes of Health.

\section{Compliance with ethical standards}

Conflict of interest The authors declare no competing interests.

Publisher's note Springer Nature remains neutral with regard to jurisdictional claims in published maps and institutional affiliations.

\section{References}

1. Periviable birth. Obstetric Care Consensus No. 6. American College of Obstetricians and Gynecologists. Obstet Gynecol. 2017;130:e187-99.

2. Marlow N. Is survival and neurodevelopmental impairment at 2 years of age the gold standard outcome for neonatal studies? Arch Dis Child Fetal Neonatal Ed. 2015;100:F82-4.

3. Torchin H, Morgan AS, Ancel P-Y. International comparisons of neurodevelopmental outcomes in infants born very preterm. Semin Fetal Neonatal Med. 2020;25:101109.

4. Kilbride HW, Aylward GP, Doyle LW, Singer LT, Lantos J. Prognostic neurodevelopmental testing of preterm infants: do we need to change the paradigm? J Perinatol. 2017;37:475-9.

5. McCormick MC, Litt JS. The outcomes of very preterm infants: is it time to ask different questions? Pediatrics. 2017;139: e20161694.

6. Jaworski M, Janvier A, Lefebvre F, Luu TM. Parental perspectives regarding outcomes of very preterm infants: toward a balanced approach. J Pediatr. 2018;200:58-63.e1.

7. Daly M. Parental perspective on neonatal outcomes. BMJ Paediatr Open. 2019;3:e00404.

8. Generic Database of Very Low Birth Weight Infants (GDB). NIH U.S. National Library of Medicine. Clinicaltrials.gov. https://www.clinicaltrials.gov/ct2/show/NCT00063063. Accessed 8 June 2020.

9. Follow-up Visit of High Risk Infants (FU). NIH U.S. National Library of Medicine. Clinicaltrials.gov. https://www.clinicaltrials. gov/ct2/show/NCT00063063. Accessed 8 June 2020.

10. Alexander GR, Himes JH, Kaufman RB, Mor J, Kogan M. A United States national reference for fetal growth. Obstet Gynecol. 1996;87:163-8.

11. Papile LA, Burstein J, Burstein R, Koffler H. Incidence and evolution of subependymal and intraventricular hemorrhage: a study of infants with birth weights less than 1,500 gm. J Pediatr. 1978;92:529-34.

12. International Committee for the Classification of Retinopathy of Prematurity. The international classification of retinopathy of prematurity revisited. Arch Ophthalmol. 2005;123:991-9.

13. Jobe AH, Bancalari E. Bronchopulmonary dysplasia. Am J Respir Crit Care Med. 2001;163:1723-9.

14. Newman JE, Bann CM, Vohr BR, Dusick AM, Higgins RD. Improving the Neonatal Research Network annual certification for neurologic examination of the 18-22 month child. J Pediatr. 2012;161:1041-6.

15. Palisano R, Rosenbaum P, Walter S, Russell D, Wood E, Galuppi B. Development and reliability of a system to classify gross motor function in children with cerebral palsy. Dev Med Child Neurol. 1997;39:214-23.

16. Palisano RJ, Hanna SE, Rosenbaum PL, Russell DJ, Walter SD, Wood EP, et al. Validation of a model of gross motor function for children with cerebral palsy. Phys Ther. 2000;80:974-85.

17. Johnson S, Moore T, Marlow N. Using the Bayley-III to assess neurodevelopmental delay: which cut-off should be used? Pediatr Res. 2014;75:670-4.

18. Younge N, Goldstein RF, Bann CM, Hintz SR, Patel RM, Smith $\mathrm{PB}$, et al. Survival and neurodevelopmental outcomes among periviable infants. N Engl J Med. 2017;376:617-28.

19. Anderson PJ, De Luca CR, Hutchinson E, Roberts G, Doyle LW. Underestimation of developmental delay by the new Bayley-III Scale. Arch Pediatr Adolesc Med. 2010;164:352-6.

20. Vohr BR, Msall ME, Wilson D, Wright LL, McDonald S, Poole WK. Spectrum of gross motor function in extremely low birth weight children with cerebral palsy at 18 months of age. Pediatrics. 2005;116:123-9.

21. Kilbride HW, Aylward GP, Carter B. What are we measuring as outcome? Looking beyond neurodevelopmental impairment. Clin Perinatol. 2018;45:467-84.

22. Stephens BE, Bann CM, Poole WK, Vohr BR. Neurodevelopmental impairment: predictors of its impact on the families of extremely low birth weight infants at 18 months. Infant Ment Health J. 2008;29:570-87.

23. Hintz SR, Kendrick DE, Vohr BR, Poole WK, Higgins RD. Community supports after surviving extremely low-birth-weight, extremely preterm birth. Arch Pediatr Adolesc Med. 2008;162:748-55.

24. Raju TNK, Mercer BM, Burchfield DJ, Joseph GF Jr. Periviable birth: executive summary of a joint workshop by the Eunice Kennedy Shriver National Institute of Child Health and Human Development, Society for Maternal-Fetal Medicine, American Academy of Pediatrics, and American College of Obstetricians and Gynecologists. Obstet Gynecol. 2014;123:1083-96.

25. Webbe J, Brunton G, Ali S, Duffy JM, Modi N, Gale C, et al. Developing, implementing and disseminating a core outcome set for neonatal medicine. BMJ Paediatr Open. 2017;1:e000048.

26. Webbe J, Brunton G, Ali S, Longford N, Modi N, Gale C, et al. Parent, patient and clinician perceptions of outcomes during and following neonatal care: a systematic review of qualitative research. BMJ Paediatr Open. 2018;2:e000343.

27. Mitra S, Reid M, McDougall B, Johnston BC. Are neonatal clinical practice guidelines truly evidence-based? A case for incorporating family values and preferences. Acta Paediatr. 2019;108:1564-6.

28. Morris BH, Oh W, Tyson JE, Stevenson DK, Phelps DL, O'Shea TM, et al. Aggressive vs. conservative phototherapy for infants with extremely low birth weight. $\mathrm{N}$ Engl J Med. 2008;359:1885-96.

29. Laparotomy vs. drainage for infants with necrotizing enterocolitis (NEST). Clinicaltrials.gov. https://www.clinicaltrials.gov/ct2/show/ NCT01029353. Accessed 8 June 2020.

30. Transfusion of prematures trial (TOP). Clinicaltrials.gov. https://www.clinicaltrials.gov/ct2/show/NCT01702805. Accessed 8 June 2020.

31. Rysavy MA, Horbar JD, Bell EF, Li L, Greenberg LT, Tyson JE, et al. Assessment of an updated Neonatal Research Network Extremely Preterm Birth Outcome Model in the Vermont Oxford Network. JAMA Pediatr. 2020;174:e196294.

32. Ment LR, Vohr B, Allan W, Katz KH, Schneider KC, Westerveld $\mathrm{M}$, et al. Change in cognitive function over time in very low-birthweight infants. JAMA. 2003;289:705-11.

33. Marlow N, Wolke D, Bracewell MA, Samara M. Neurologic and developmental disability at six years of age after extremely preterm birth. N Engl J Med. 2005;352:9-19. 
34. Shah PS. Neonatal intensive care-the only constant is change. $\mathrm{N}$ Engl J Med. 2017;376:694-6.

35. Haslam MD, Lisonkova S, Creighton D, Church P, Yang J, Shah PS, et al. Severe neurodevelopmental impairment in neonates born preterm: impact of varying definitions in a Canadian cohort. $\mathbf{J}$ Pediatr. 2018;197:75-81.e4.
36. DeMauro SB, Schmidt B. Comparing like with like when reporting neurodevelopmental outcomes after preterm birth. J Pediatr. 2018;197:10-2.

37. Spencer-Smith MM, Spittle AJ, Lee KJ, Doyle LW, Anderson PJ. Bayley-III cognitive and language scales in preterm children. Pediatrics. 2015;135:e1258. 